\title{
THE NECESSITY FOR A SEXUAL HARASSMENT ACT IN MALAYSIA
}

\author{
Sarvinder Kaur*
}

\begin{abstract}
Sexual harassment is a major problem at the workplace. The options of recourse available to a person subjected to sexual harassment are: complaining to the employer, complain to the Labour Department, pursuing criminal proceedings under the Penal Code and commencing action under the law of tort. All of these options are not conducive. In 1999 the Ministry of Human Resources launched the Code of Practice on the Prevention and Eradication of Sexual Harassment in the workplace. The aim is to provide guidelines to employers on the establishment of in-house mechanisms at the company level to prevent and eradicate sexual harassment in the workplace. While the Code has been the first concrete step towards recognising the seriousness of the issue, it is a voluntary code and the Ministry cannot compel companies to adopt it. A proposed Sexual Harassment Bill, which could give effect to the United Nations Convention on the Elimination of All Forms of Discrimination against Women that seeks to eliminate as far as possible discrimination
\end{abstract}

Senior Lecturer, Department of Government and Civilization Studies, Faculty of Human Ecology, University Putra Malaysia. 
involving sexual harassment in the workplace, was rejected by Parliament. In the absence of a specific statute, sexual harassment at the workplace is often dealt with as dismissal cases under the Industrial Relations Act 1967. This prevents our courts from dealing with sexual harassment issues such as the burden of proof, definition and other matters. This is important as many sexual harassment cases are unreported because of unawareness on the part of the victim as to whether the action actually constituted sexual harassment, and if so, where to complain and what to do. Apart from the legal implications of sexual harassment, sexual harassment could also affect the well-being of the victim.

\section{INTRODUCTION}

Sexual harassment generally means unwelcome sexual conduct. Sexual harassment has been defined in various terms. The International Labor Organisation (ILO) refers to sexual harassment as a violation of the fundamental rights of workers, a safety and health hazard, a problem of discrimination, an unacceptable working condition, and a form of violence, usually against women workers. The menace of sexual harassment has also been given due recognition by the United Nations in its Convention on the Elimination of All Forms of Discrimination Against Women (CEDAW) which specifically provides for the elimination, as far as possible, of discrimination involving sexual harassment in the workplace, in educational institutions and in other areas of public activity and the promotion of recognition and acceptance within the community of the principle of the equality of women and men.

In the domestic context, many countries individually have enacted laws which specifically prohibit sexual harassment and provide precise definitions as to what amounts to sexual harassment. In the United States, sexual harassment is prohibited by Title VII of the Civil Rights Act 1964, which recognises two types of sexual harassment: first, sexual coercion (quid pro quo), which is an employment discrimination as it directly affects the victims employment status; secondly, sexual annoyance which is not directly connected to loss of employment benefits but creates a 
hostile working environment. In Malaysia, the absence of specific legislation on sexual harassment has deprived Malaysian courts from dealing with cases of sexual harassment, such as interpreting the facts of a case expressly based on the definition of sexual harassment. In Malaysia, cases involving sexual harassment are normally dealt with under the Criminal law (Penal Code), the law of Tort or as an employment dismissal matter under the Industrial Relations Act 1967.

Under the Penal Code, complaints are dealt with as assault, ${ }^{1}$ outrage on modesty, ${ }^{2}$ outraging of decency, ${ }^{3}$ criminal intimidation ${ }^{4}$ and using words or gestures to insult the modesty of a woman. ${ }^{5}$ The closest offence under the Penal Code is section 509 which provides:

whoever, intending to insult the modesty of any women, utters any words, makes any sound or gesture or exhibits any object, intending that such word or sound shall be heard, or such gesture or object shall be seen by such women, shall be punished with imprisonment for a term which may extend to five years or with a fine, or with both.

However, criminal law is not a preferred choice as it involves a high burden of proof and the requirement of intention. Furthermore, the nature of criminal law is to punish the offender rather then compensating the victim which is normally preferred by the victim especially if she/he had suffered loss, for instance loss of job and salary. Alternatively, pursuing an action of sexual harassment under the private law of tort may be a more preferred choice but a costly one, as the victim will have to hire her/his own lawyer and endure a lengthy litigation process. Sexual harassment at the workplace can sometimes result in dismissal of the victim. The victim may resign due to unbearable sexual harassment in the office that creates a hostile environment, or her/his employment may be terminated due to it, despite of the person being the victim. In such

Section 351.

Section 354.

Section 377.

Section 503.

Section 509. 
circumstances, the victim may have recourse to the Industrial Relations Act 1967 which provides that when a work person has been dismissed without just cause or excuse he may apply to be reinstated to her/his former employment.

However, it is to be noted here that The Industrial Relations Act 1967 applies only to the private sector. The public sector is subject to the Service Circular No. 22 of 2005, issued by the Public Service Department of Malaysia. It provides guidelines for dealing with sexual harassment at the workplace and makes reference to the Public Officers (Conduct and Discipline) Regulations 1993. Rule 4A of the Regulations expressly forbids sexual harassment among officers in the civil service.

In 1999, the Malaysian Ministry of Human Resources launched the Code of Practice on the Prevention and Eradication of Sexual Harassment in the Workplace, ${ }^{6}$ which provides guidelines for private companies in dealing with sexual harassment at their workplace. However, this is only a voluntary Code, and does not carry the force of law. This means that the individual company may choose to implement this Code in its workplace, at its discretion.

This Code allows the employer to tailor the provisions of the Code to suit its own sexual harassment policy, thus resulting in the inconsistency of policy from one company to another. A survey carried out by All Women's Action Society (AWAM) and Women's Development Collective (WDC) ${ }^{7}$ found that the time frame in carrying out the complaint procedure differed from one company to another considerably, from the total period ranging from as short as 16 days to as long as 112 days. Another example for inconsistency is the number of opportunities given to the harasser. One company has provided five opportunities to the harasser before he is charged, while in another company a written apology suffices if both parties are agreeable to reconcile, but the harassed is immediately charged if it is the second offence. In yet another company,

The Code was the result of collaboration between many organizations, including the Malaysian Trade Union Congress and the Malaysian Employers' Federation (MEF) under the auspices of the Ministry of Human Resources.

$7 \quad$ Cecelia Ng, Zanariah Mohd Nor \& Maria Chin Abdullah, A Pioneering Step: Sexual Harassment and The Code of Practice in Malaysia, Women's Development Collective, Kuala Lumpur, 2003. 
if the perpetrator is from the management, he is immediately fired. Therefore the Code should try to narrow the range of inconsistency.

The Code mentions in Article 32 that the employer should adopt a consultative approach by involving trade unions. This is a very general requirement, as many employers may want to limit the involvement of trade unions to merely 'consultation purposes' and avoid direct interference. The better approach would have been for the trade unions or any other independent body to check and verify the procedures implemented by the employers to ensure a degree of uniformity.

It is submitted that access to the complaints body should be by various options, for example, in person, via e-mail, by phone or by writingin. Confidentiality is another important factor because victims may find it embarrassing if their predicaments become public. The Code apparently has failed to guarantee these.

The Code has failed to establish an independent body to look into the implementation of the relevant procedures in a company. It is submitted that the complaints body should not only be the employer (inhouse), because if the victim believes that there will be prejudice or is not comfortable with complaining to the in-house body, there should be an alternative party which could work together with the in-house body.

Article 18(iii) of the Code mentions that the company should establish "an appeal procedure to enable dissatisfied party to appeal against the outcome of an investigation to a higher authority." However, it fails to define the nature of the 'higher authority.'

It should be noted that the Code has very well laid down the disciplinary rules and penalties as well as protective and remedial measures for the victims of sexual harassment.

A more comprehensive instrument to deal with sexual harassment was presented to the Ministry of Human Resources by the Joint Action Group Against Violence Against Women (J.A.G.) ${ }^{8}$ in March 2001. It was the proposed Bill on Sexual Harassment. The Bill dealt with matters such as vicarious liability, complaints procedure, procedure after complaint, conciliation, inquiry, enforcement, appeals and others. However, as the

$8 \quad$ JAG comprises of Women's Center for Change, Penang, Women's Development Collective, Women's Aid Organisation, AWAM, Sisters In Islam, MTUC, Persatuan Sahabat Wanita Selangor and Women’s Candidacy Initiative. 
Bill was seen as a step forward in eradicating sexual harassment, it was not passed by Parliament, with the promise that provisions on sexual harassment will be mentioned in the existing Employment Act 1955.

The Bill is more comprehensive as compared to the Code, whereby it has remedied some of the shortcomings of the Code, such as having a detailed step by step procedure with specific time frames and it is not limited to internal complaints procedure but includes external procedure of complaint. It is divided into seven parts with various divisions.

Part 1 comprises the interpretation of various terms such as who is regarded as an "employer" and "employee," what is meant by "complaint" and "complainant" and what is a "workplace."

Part 2 defines sexual harassment as:

Unwanted verbal or non-verbal or physical conduct of a sexual nature with the purpose or effect of violating the dignity of a person or creating an intimidating, hostile, degrading, humiliating or offensive environment.

Part 3, division 1 protects against victimisation of complainants or persons associated with the complaint of sexual harassment (for example, a person giving evidence). Division 2 prohibits authorising or assisting sexual harassment. Division 3 dwells on the issue of burden of proof. Section 21 lays down the principle of vicarious liability. This means that when a person in the course of employment contravenes the Bill, that person and the employer or principal must be taken to have contravened the provisions, and the complaint may be lodged against either or both of them. Section 22 provides the exception where an employer or principal is not held vicariously liable for the actions of the employee if the employer/principal can prove on the balance of probabilities that the employer/principal had taken reasonable precautions to prevent the act of the employee and had also taken reasonable action upon receipt of a complaint relating to sexual harassment.

Part 4 mentions the appointment of a Director on sexual harassment by the Yang DiPertuan Agong and an Assistant Director by the Minister. The duties of the Director includes inter-alia advice and making recommendations to the Minister on matters of sexual harassment, consultation, and inquire into discriminations and the effects of sexual harassment. 
Under section 31, the Director is required to submit a report, on the operation of the Bill to the Minister annually which is to be tabled in each House of Parliament within 14 days of receipt of the report or commencement of the next session of Parliament.

Part 5, division 1 of the Bill lays down a simplified step by step procedure. It explains what the victim has to do as well as the duties of the Director and the Tribunal with relevant time frames. This Part comprises 6 divisions: making a complaint, procedure after complaint, conciliation, inquiry, enforcement of award, and review and miscellaneous other matters. Division 1 allows a complaint to be made directly, which means that it may bypass the internal mechanism, i.e, complaining to the employer or the committee, although reasons for forsaking such remedies may be required. This is an important provision because it can prevent prejudices in the company. Among reasons why victims of sexual harassment do not pursue action in their predicament is the fear of being shunned by co-employees, the fear that the company may not believe them or that the company may decide not to take any action at all. Therefore, in the event that a victim is fearful of the reactions of the company especially when the harasser is a person holding a high rank in the company, and she believes that there is a possibility of bias, she can safely invoke division 1 of Part 5.

The victim of sexual harassment is allowed to withdraw her complaint stating her reasons for doing so, and the Director shall investigate to ensure that the withdrawal is made voluntarily. Investigation of withdrawal by the Director is an important provision as it tends to oust any suspicious withdrawal.

Division 3 requires the Director to attempt to resolve the issue by conciliation within 60 days from the completion of the investigation, and section 43 requires parties to represent themselves, who may not be represented by an advocate, adviser, consultant or by any other person whatsoever. This would save time, cost and ensure receipt of first hand information.

In the event that the conciliation fails, or the nature of the case requires it to be referred for inquiry or when it is requested by complainant, the Director refers the complainant to the Tribunal for inquiry. Although the hearing of the inquiry is to be held in public unless otherwise directed by the Tribunal and a person may be represented by an Advocate etc., the inquiry is held with little formalities and without delay. Therefore it is different from lengthy court proceedings. 
As to the burden of proof, section 56 provides:

i. A person who raises an issue at an inquiry is to prove that issue on a balance of probabilities;

ii. It is not necessary for evidence of sexual harassment to be corroborated before a respondent can be found liable in a sexual harassment complaint.

Not having a legal instrument can be detrimental to a victim of sexual harassment. As will be seen, the application of section 56 of the Bill, that no corroboration is necessary, could have settled the problem in the Malaysian landmark case of Jennico Associates Sdn. Bhd. v. Lilian Therera De Costa. ${ }^{9}$ This case was decided to the disadvantage of the victim where the High Court held that an allegation of sexual harassment must be adequately corroborated and that to reply on the uncorroborated evidence of the complainant alone would be very dangerous. An appeal to the Court of Appeal was unanimously dismissed.

It is evident that a lot of care should be taken in cases pertaining to sexual offences as there is the likelihood of 'made up stories' or 'exaggerated' facts being presented in order to frame another. However, the requirement for corroboration in a case of sexual harassment could be out of place since not many would commit such an offence in the sight of a third person. Even if corroboration that is required is in the nature that another has been duly informed of the incident 'immediately' (as was mentioned by the Court) who gives evidence in court of the same although the latter did not witness the incident of sexual harassment, it could still be unrealistic. This is because in the Asian society, anything sexual in nature is not discussed openly, less so by women. Often, women are blamed for the offence due to reasons such as dressing inappropriately, thus inviting sexual advances. Furthermore, the dominant, patriarch, male stereotype is still very much alive in the Asian society.

A number of cases have been pursued in the Malaysian courts on the basis of sexual harassment, where the courts have favoured the victim. In the case of Sitt Tatt Bhd. v. Flora Gnanapragasam \& Another ${ }^{10}$ the Malaysian High Court in confirming the decision of the

9 Jennico Associates Sdn. Bhd. v. Lilian Therera De Costa [Award No. 606 of 1996].

$10 \quad$ Sitt Tatt Bhd. v. Flora Gnanapragasam \& Another [2005] 7CLJ 522. 
Industrial Court held that if an employer fails to resolve a complaint of sexual harassment of an employee, that employee can claim constructive dismissal. Among the issue adduced by the company in this case was the delay on the part of the complainant to raise the issue of sexual harassment and the failure to lodge a police report. To this the learned Chairman of the Industrial Court responded that the law does not require the complainant to lodge a police report and that it is the duty of the senior Management Officers of the company to take remedial measures upon a complaint of sexual harassment. The complainant is not guilty of any dereliction but the officers are. The complainant was awarded back wages in lieu of reinstatement.

Again, in the case of Melewar Corporation Bhd. v. Abu Osman $^{11}$ the court again emphasized the duty of employer in safeguarding its employees against sexual harassment. In this case, upon complaints of sexual harassment, a domestic inquiry was held, which found the claimant to be guilty of sexual harassment, including physically molesting female staff by touching parts of their bodies and making lewd suggestions and verbal advances, sexual in nature. On the recommendation of the panel of inquiry the claimant was demoted and transferred to another company. When this matter reached the Industrial Court, the Learned Chairman emphasised the contractual obligation of the employer towards the employee to provide a safe and conducive working environment. Therefore, the failure to stop acts of sexual harassment which had been brought to the attention of the employer would amount to a breach of contract. This entitles the employee to seek remedies because the employer is deemed to have constructively dismissed the employee.

\section{IN THE ABSENCE OF SPECIFIC LAWS}

The main problem that arises in the absence of specific law is the loss of the opportunity to commence legal action directly based on the actual offence, in this case sexual harassment. As seen earlier, most sexual harassment cases are dealt with as dismissal from work, rather than sexual harassment at the workplace. This means that the consequences of sexual harassment was discussed rather than the act 
of sexual harassment itself, which calls for a person to resign first, pursuing a case of sexual harassment thereafter as an element of that resignation.

Sexual harassment should be dealt with as a separate category of illegal behaviour as was done in the Indian case of Vishaka v. State of Rajasthan. ${ }^{12}$ India does not have a specific law prohibiting sexual harassment, although the Indian Constitution prohibits discrimination based on sex and guarantees just and humane conditions of work. The Indian Court did a remarkable job in this landmark case where the Supreme Court used the United Nations Convention on the Elimination of All Forms of Discrimination against Women to establish detailed guidelines prohibiting sexual harassment, including the meaning of sexual harassment and the requirements for processing sexual harassment complaints. These guidelines were meant to be used for enunciating laws regarding sexual harassment in India.

Malaysia, being a member country of the United Nations, has ratified several United Nations Conventions including The Convention on the Elimination of All Forms of Discrimination against Women (CEDAW). CEDAW came into force in 1981 and was ratified by Malaysia with some reservations in 1995. CEDAW aims to eliminate discrimination against women in all forms including politics, economics, employment, cultural fields, public life, education, health and family. It urges state members to condemn discrimination against women in all its forms and to pursue by all appropriate means and without delay a policy of eliminating discrimination, to embody the principal of the equality of men and women through national constitutions or legislation, or by other appropriate means. CEDAW, in its preamble, has mentioned that:

...discrimination against women violates the principles of equality of rights and respect for human dignity, is an obstacle to the participation of women, on equal terms with men, in the political, social, economic and cultural life of their countries, hampers the growth of the prosperity of society and the family and makes more difficult the full development of the potentialities of women in the service of their countries and of humanity. 
In Japan, several legislations were enacted to bring Japanese law into conformity with the Convention, such as the amendment to the Nationality Law in 1984, which conferred Japanese nationality on the children of Japanese women. In China, the Chinese Constitution's guarantee of gender equality and China's obligation under CEDAW prompted the passing of the law on the Protection of Women's Rights and Interest in 1992. In Australia, in the case of Aldridge v. Booth ${ }^{13}$ the Court was asked to declare the sexual harassment provisions of Australia's new Sex Discrimination Act unconstitutional, because the Federal Government was prohibited from passing national legislation in the area of sexual harassment in employment. However, the court upheld the Sex Discrimination Act, agreeing with the Government that CEDAW ratification had effectively expanded its ability to pass national laws regarding women's human rights. The court found that this power extended, specifically, to the Government's obligation regarding the prevention of sexual harassment under CEDAW. Since the CEDAW Committee has defined sexual harassment as discrimination in a General Recommendation, and article 4 of CEDAW requires states to eliminate all forms of discrimination against women, the Government therefore had both the authority and the obligation to pass a national law prohibiting sexual harassment.

The absence of specific law on sexual harassment also prevents our courts from dealing with the elements of sexual harassment itself. The Parliament passes a law, but the interpretation of the law is done by the Courts. For instance, the generally accepted definition of sexual harassment is 'unwelcome sexual conduct,' which is also mentioned in the Malaysian Code of Practice on the Prevention and Eradication of Sexual Harassment in the Workplace. What amounts to 'unwelcome sexual conduct' will depend on the facts of a case, for the courts to interpret. What may be deemed as sexual harassment by one may not be deemed as such by another. A comment about a woman's dress may be taken as mere flirtation by one woman even when it may seem offensive, when she is able to tolerate it and dismiss the statement altogether, but another woman may take it as a sexist statement that she totally disapproves, thus it may have a negative effect on her. 
A precise definition is important because many women fail to recognize sexual harassment when it occurs. A precise complaints procedure is also important as most victims generally do not know what to do when subjected to sexual harassment, or they are too embarrassed or afraid to do anything when sexually harassed. In Malaysia, Marican ${ }^{14}$ found that while $83.1 \%$ of men and $87.7 \%$ of women had experienced one form of sexual harassment, only 5.2\% of male and 30\% of women labeled the incident as sexual harassment. The figures here obviously speak volumes.

\section{SEXUAL HARASSMENT AND THE WELL-BEING OF WORKING WOMEN}

A recent research on sexual harassment showed that women's well-being is affected when they are sexually harassed at workplace. ${ }^{15}$ This research was done on thirty working women who are married with children in Kuala Lumpur. The age of the participants ranged from 24 years to 46 years with a mean of 32.40 years and a standard deviation of 5.37 years. The number of years of employment in their present occupation showed a range of one to 20 years with a mean of 6.67 years and a standard deviation of 4.53 years. Total number of years of employment showed that participants had worked in the range of one to 25 years in total with a mean of 10.77 years and a standard deviation of 5.54 years. Participants' hours spent at workplace ranged from seven to 11 hours per day with a mean of 8.53 hours and a standard deviation of 0.90 hours.

The questionnaire method of survey was applied. Among questions asked were whether the participants or someone they knew had experienced sexual harassment; the awareness of sexual harassment

$14 \quad$ Sabitha Marican, persepsi gangguan seksual antara lelaki dan wanita di tempat kerja. Paper presented at National Seminar on Malaysian Women in the New Millenium, 16-17 September 2000, Petaling Jaya, Malaysia.

15 Sarvinder Kaur, Malaysian employment legislation for women at work: A socio-legal study on Malaysian secretaries/ clerks. Thesis for the degree of Doctor of Philosophy. IIUM, 2006. 
and the sexual harassment policy available at their workplace; what they would do if subjected to sexual harassment; how can the problem of sexual harassment be solved and by whom; and if they were subjected to sexual harassment, how will it affect them and their job.

Results showed that thirty participants knew of someone who had experienced sexual harassment and two participants admitted experiencing sexual harassment themselves. When asked what the actions taken by victims were, all reported that they only confided the incidents to their close friends and dismissed them as being not serious because they did not want to create a hostile work environment. However, participants who had experienced sexual harassment reported experiencing it only once.

All participants reported that their company had a policy against sexual harassment but only six participants reported that apart from the company policy on sexual harassment, their company also created awareness about sexual harassment. The other participants reported that they only knew of the sexual harassment policy when they read the company regulation book provided to them, upon starting employment in that company.

An interviewee, aged 35 years with two children, a secretary who has been in employment for 12 years, admitted that if she was subjected to minor sexual harassment she would ignore it unless if it persisted, in which event she would take action as mentioned in the company's sexual harassment policy. However, if the sexual harassment was serious, then she would not hesitate to proceed immediately as per the policy. She considered sexual harassment involving touching or verbal comments directed particularly at her as 'serious' harassment but mere verbal comments directed at women in general as 'minor' harassment. ${ }^{16}$

All participants were happy that their companies had sexual harassment policies. However since there had not been any reported

16 Sarvinder Kaur, Malaysian employment legislation for women at work: A socio-legal study on Malaysian secretaries/ clerks. Thesis for the degree of Doctor of Philosophy. IIUM, 2006, 231. 
cases on sexual harassment so far, they were unable to determine the effectiveness of the policies. Apart from their company policies on sexual harassment, all participants were unaware of any other policies, regulations or laws that protected women specifically against sexual harassment.

Although the participants were satisfied with their company policies on sexual harassment, they were worried regarding the outcome of the complaints if the harassment was done by a person of a higher rank on a person of a lower rank the company.

An interviewee, aged 36 years, with four children, who has been in employment as a clerk for the past 16 years, raised her concern about the application of the policy. She said that since the policy was made by the company, it may bend the policy or apply it according to its convenience depending on who was involved. Therefore, she believed that an Act of Parliament would be preferred as compared to policies adopted by companies themselves. ${ }^{17}$

Participants reported that if they were subjected to sexual harassment they would feel uneasy, worried, scared, embarrassed, disgusted, unsecured, disrespected and would be inclined to consider changing their jobs. One participant commented that it would trouble her a lot, and when asked what that would lead to, her reply was "eating disorder."

The above research shows that many women suffer in silence when sexually harassed, resulting in their negative well being. A study by Strauss ${ }^{18}$ shows that adolescent females who had been sexually harassed reported feelings similar to those experienced by rape victims. Decreased feelings of competence and confidence and increased feelings of anger, frustration, depression and anxiety all can result from harassment along with a sense of self-blame, especially among women with traditional sex

17 Sarvinder Kaur, Malaysian employment legislation for women at work: A socio-legal study on Malaysian secretaries/ clerks. Thesis for the degree of Doctor of Philosophy. IIUM, 2006. 232. for Principals,” NSSP bulletin 72, (1998):506. 
role beliefs. ${ }^{19}$ These emotions in turn can leave in their wake a decreased ability to concentrate and a sense of listlessness. ${ }^{20}$

\section{CONCLUSION}

The presence of legislation to improve the well-being of employed women is important because decreased well-being is detrimental to these women, their families and their employers, due to symptoms such as poor health, increased stress and decreased job satisfaction. Laband and Lentz, ${ }^{21}$ found sexual harassment to be negatively related to job satisfaction among female lawyers in the United States. Reduced job satisfaction can cause absenteeism, lower productivity, high worker turnover, low morale and the like.

Awareness about sexual harassment should be inculcated in every worker (male and female). Every worker should know what constitutes sexual harassment and what to do in the event they are sexually harassed. Workers, especially women should be assured that it is important and necessary to report incidence of sexual harassment. This is because the Asian culture and tradition essentially encourages women to keep a 'low profile,' especially in sexual related matters.

In view of the problems highlighted in this article, it is evident that legislation is urgent. The Parliament, when rejecting the Bill on sexual harassment, had agreed to incorporate the provisions of sexual harassment into the existing Employment Act of 1955. It is submitted that incorporating an extensive topic such as sexual harassment in an existent piece of legislation is grossly inadequate. The proposed Bill mentioned earlier could indeed be a more effective tool in reducing incidents of sexual harassment, in addition to educating the public on the issue.

$19 \quad$ Stephanie Riger, "Gender Dilemmas in Sexual Harassment Policies and Procedures,” American Psychologist, (1991):46.

20 Kathy Hotelling, "Sexual Harassment: A problem shielded by silence," Journal of counseling and development. (1991):69.

21 David N. Laband \& Bernard F. Lentz, "The effects of sexual harassment on job satisfaction, Earnings, and turnover among female lawyers,” Industrial and labour relations review, 51(4), (1998): 594-607. 